\title{
COMPARATIVE ANALYSIS OF SPLIT-WINDOW AND SINGLE-CHANNEL ALGORITHMS FOR LAND SURFACE TEMPERATURE RETRIEVAL OF A PSEUDO-INVARIANT TARGET
}

\author{
Pâmela Suélen Käfer ${ }^{1}$ - ORCID: 0000-0002-4932-8715 \\ Silvia Beatriz Alves Rolim ${ }^{1}$ - ORCID: 0000-0002-2146-9057 \\ Lucas Ribeiro Diaz ${ }^{1}$ - ORCID: 0000-0002-8091-9011 \\ Nájila Souza da Rocha ${ }^{1}$ - ORCID: 0000-0002-6381-1412 \\ María Luján Iglesias ${ }^{1}$ - ORCID: 0000-0001-7560-101X \\ Franciel Eduardo Rex ${ }^{2}$ - ORCID: 0000-0003-0876-8500 \\ ${ }^{1}$ Universidade Federal do Rio Grande do Sul, Centro Estadual de Pesquisas em Sensoriamento Remoto e \\ Meteorologia, Porto Alegre - Rio Grande do Sul, Brasil. \\ E-mail: pamelaskafer@gmail.com; silvia.rolim@ufrgs.br; lucas.diaz@ufrgs.br; najila.rocha@ufrgs.br; \\ lujaniglesias@gmail.com \\ ${ }^{2}$ Universidade Federal do Paraná, Departamento de Ciências Florestais, Curitiba - Paraná, Brasil. \\ E-mail: francielrexx@gmail.com
}

Received in 05 ${ }^{\text {th }}$ July 2019

Accepted in 09th May 2020

\begin{abstract}
:
Land surface temperature (LST) acquired from remote sensing observations is essential to monitor surface energy and water exchange processes at the land-atmosphere interface. Most LST retrieval methodologies are developed focusing on Northern hemisphere. Consequently, Southern hemisphere has a great need for investigating the performance of LST retrieval algorithms already consolidated in the literature. In this paper, we compared a Splitwindow (SW) and a Single-channel (SC) method to retrieve LST from Landsat 8 OLI/TIRS images in a dune field, Southern Brazil. To validate the results, the Atmospheric Correction Parameter Calculator (ACPC) tool and Radiative Transfer Equation (RTE) were used. Results demonstrated that both methodologies are in accordance with the RTE, despite they overestimated the LST. Analysis of variance (ANOVA) indicated that the means are not statistically significant ( 0.05 level). The correlations between LST retrieved and RTE were strong, producing $R^{2}$ of 0.984 and 0.973 for the SW and SC, respectively, and RMSE values of 1.18 and 1.6. SW also exhibited the best values of MSD $( \pm 0.983)$ and Bias (0.773), thus reinforcing its superior performance. SW can be applied with an accuracy of $1.18 \mathrm{~K}$ in Southern Brazil, without needing complex modeling or specific radiosonde.
\end{abstract}

Keywords: Thermal infrared region; LST; Emissivity; Atmospheric correction; Dunes.

How to cite this article: KÄFER, P. S.; ROLIM, S. B. A.; DIAZ, L. R.; ROCHA, N. S.; IGLESIAS, M. L.; REX, F. E. Comparative analysis of split-window and single-channel algorithms for land surface temperature retrieval of a pseudo-invariant target. Bulletin of Geodetic Sciences. 26(2): e2020008, 2020 


\section{Introduction}

Information about land surface temperature (LST) acquired from remote sensing satellite observations is very important to monitor surface energy and water exchange processes at the land-atmosphere interface (Zhao et al. 2019). In addition, it is a key variable to be retrieved from the Thermal Infrared (TIR) data because is widely used in many scientific fields including evapotranspiration, climate change, hydrological cycle, vegetation monitoring, urban climate and environmental studies, among others (Jiménez-Muñoz et al. 2008; Cristóbal et al. 2009; Li et al. 2013; Grondona et al. 2016; Ndossi and Avdan, 2016). LST also helps to analyze the climate change such as global warming (Chen et al. 2016) and thus is selected as one of Essential Climate Variables by the World Meteorological Organization (WMO) (Kim et al. 2019).

The LST variable reflects the amount of radiation emitted from the surface and sub-surface of the earth, and the exchange of energy between the earth surface and atmosphere (Weng et al. 2019). Remote sensing in the TIR region provides an opportunity to obtain information about this variable. In this context, several efforts have been devoted to establishing methods to retrieve the LST from remote sensing data. These algorithms can be roughly grouped into three categories according to Li et al. (2013) and Du et al. (2015): (i) single-channel (SC) (ii) multichannel, and (iii) multi-time methods. The split-window (SW) methods are included in the group (ii).

The SW methods use two TIR bands typically located in the atmospheric window between 10 and $12 \mu \mathrm{m}$. The basis of the technique is that the radiance attenuation for atmospheric absorption is proportional to the radiance difference of simultaneous measurements at two different wavelengths (Jiménez-Muñoz et al. 2014).

In contrast, SC methods use the radiance measured by the sensor in a single channel and corrects the radiance for residual atmospheric attenuation using atmospheric transmittance/radiance code that requires input data on the atmospheric profiles. These profiles are obtained by launching in situ radiosondes. Then, the LST is retrieved from the radiance measured in this channel by inverting the Radiative Transfer Equation (RTE).

Nevertheless, atmospheric profiles data hardly ever are available for specific conditions in the real world (Wang et al. 2015) and to be suitable they need to be launched simultaneously with the satellite overpass (Sobrino et al. 2004). In order to avoid the radiosonde dependence SC algorithms were developed in the last three decades (Qin et al. 2001; Jiménez-Muñoz and Sobrino 2003; Cristóbal et al. 2009; Jiménez-Muñoz et al. 2014; Wang et al. 2015; Cristóbal et al. 2018).

Given that the atmosphere is the main problem in the TIR remote sensing, to acquire reliable estimates of LST from satellite measurements, atmospheric, angular and emissivity effects must be compensated (Li et al. 2013). SW methods are more popular due to its simplicity and precision. However, SC methods may be more accurate as long as they have sufficient data relative to the atmosphere state (Dash et al. 2002) and robust assumptions based on physics.

The Landsat series of satellites has been one of the major contributing factors in the development of globalscale earth systems science research (Malakar et al. 2018). For Landsat 4, Landsat 5, and Landsat 7 data, there was only one thermal infrared channel, and only the SC methods are suitable to derive LST (Zhang et al. 2016; Cristóbal et al. 2018). On the other hand, Landsat 8 has two spectrally adjacent channels in the TIR region (Jiménez-Muñoz et al. 2014), thus allowing to apply both SW and SC methods.

If radiosonde data is unavailable, in order to apply SC methods an option currently for Landsat series of satellites is to use the freely online tool Atmospheric Correction Parameter Calculator (ACPC) (https://atmcorr.gsfc. nasa.gov/) developed by Barsi et al. (2005) that creates interpolated vertical profiles through the National Center for Environmental Prediction (NCEP) reanalysis data (Zhang et al. 2016; Cristóbal et al. 2018).

Differently from the North, the South hemisphere (specially Brazil) has a big gap in LST field data, which makes the field validation of satellite measurements a challenge. As in situ data are unavailable, the web-based ACPC 
becomes very useful tool for the atmospheric correction of Landsat TIR data, since it can achieve satisfactory results in retrieving LST (Barsi et al. 2005; Jiménez-Muñoz et al. 2010). Therefore, some studies have been using the ACPC as a reference (Sánchez et al. 2009; Weng and Fu 2014; Zhang et al. 2016; Bisquert et al. 2016; Sheng et al. 2017).

Most LST retrieval methodologies are developed and validated focusing on North hemisphere. As a result, Southern hemisphere has a great need for investigating the performance of LST retrieval algorithms already consolidated in the literature (Käfer et al. 2019). In this paper, we aimed to compare a SW and a SC method to retrieve LST from Landsat 8 OLI/TIRS images. To validate the results obtained, the ACPC tool (Barsi et al. 2005) was used.

\section{Material and methods}

\subsection{Theoretical Background}

The land surface is not a perfect blackbody for thermal emittance. Therefore, the LST retrieval from the observed thermal radiance in space is more complicated. The atmosphere and ground effects must be considered (Li et al. 2013; Wang et al. 2015).

For a cloud-free atmosphere under local thermodynamic equilibrium, the thermal radiance observed at the top of the atmosphere (TOA) can be expressed according to the RTE, which represents the basis of the SC methods (Li et al. 2013; Zheng et al. 2019). Thus, RTE is applied to a certain sensor channel and wavelength interval according to

$$
L_{s e n, \lambda}=\left[\varepsilon_{\lambda} B_{\lambda}\left(T_{s}\right)+\left(1-\varepsilon_{\lambda}\right) L_{a t m, \lambda}^{\downarrow}\right] \tau_{\lambda}+L_{a t m, \lambda}^{\uparrow}
$$

where $L$ sen is the at-sensor radiance in $\mathrm{Wm}^{-2} \mu \mathrm{m}^{-1} \mathrm{sr}^{-1}, \varepsilon$ is the land surface emissivity (LSE) at a certain wavelength interval $\lambda, B \lambda(T s)$ is the Planck's law, $L \downarrow$ is the downwelling atmospheric radiance in $W^{-2} \mu^{-1} \mathrm{sr}^{-1}, L \uparrow$ is the upwelling atmospheric radiance in $\mathrm{Wm}^{-2} \mu \mathrm{m}^{-1} \mathrm{sr}^{-1}$, and $\tau$ is the atmospheric transmittance.

In most of the conditions, the specific data of study areas during the satellite overpass time are missing, the Atmospheric Correction Parameter Calculator (Barsi et al. 2005) has been successfully used to simulate the atmospheric conditions (Jiménez-Muñoz et al. 2010; Ndossi and Avdan, 2016; Zhang et al. 2016). Thus, with the required variables, the land surface radiance, $L \lambda(T S)$ is calculated as

$$
L_{s e n, \lambda}(T s)=\frac{L_{\lambda-} L_{a t m \uparrow}}{\tau \varepsilon_{\lambda}}-\frac{1-\varepsilon_{\lambda}}{\varepsilon_{\lambda}} L_{a t m \downarrow}
$$

Afterwards, through the inversion of Planck's equation, the LST is obtained

$$
B_{\lambda}(T s)=\frac{C_{1}}{\lambda^{5}\left[\exp \left(\frac{C_{2}}{\lambda T}\right)-1\right]}
$$

where $B \lambda(T)$ is the spectral radiance $\left(\mathrm{W} \mathrm{m}^{-2} \mu \mathrm{m}^{-1} \mathrm{sr}^{-1}\right)$ of a black body at temperature $T$ in kelvin and wavelength $\lambda$ in $\mu \mathrm{m} ; C 1$ and $C 2$ are physical constants $\left(C 1=1.191 \times 10^{8} \mathrm{~W}_{\mu \mathrm{m}^{4}} \mathrm{sr}^{-1} \mathrm{~m}^{-2}, \mathrm{C} 2=1.439 \times 10^{4} \mu \mathrm{m} \cdot \mathrm{K}\right)$.

\subsection{Pseudo-invariant target}

The study area is a dune field located in the North Coast of Rio Grande do Sul state, Brazil (Figure 1). The site has a large stock of fine quartz sand (125 to $250 \mu \mathrm{m})$, composed by quartz $(99.53 \%)$ and heavy minerals $(0.47 \%)$, 
with grains varying among sub-rounded (68\%), rounded (18\%), subangular (14\%) (Käfer et al. 2019). The dunes are arranged side by side and are moving by the action of the wind, mobilizing the sandy particles.

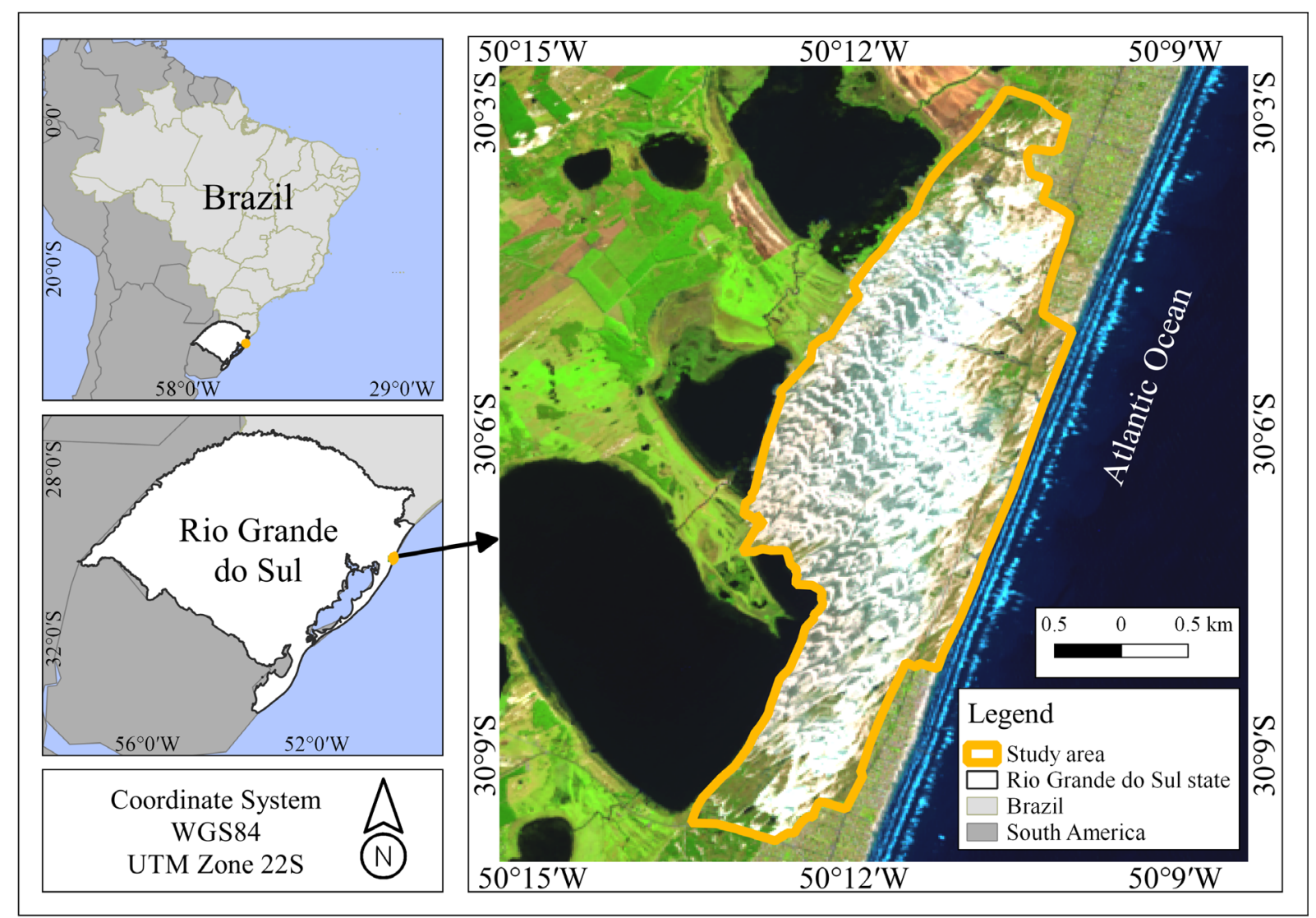

Figure 1. Dune area location in Southern Brazil. Dune mask shown by the yellow line. Landsat $8 \mathrm{OLI}-$ color composite RGB654 (USGS, 2019).

In mineral mapping studies, the behavior of minerals and the observed spectral features have been found to be correlated, especially for silicates. These features are related to the differences in the SiO content in the soil, which has minimal emissivity and therefore maximum absorption (reststrahlen effect).

This behavior is observed in silicates, such as quartz, having reststrahlen effects observed around $8,2 \mu \mathrm{m}$ and $9,3 \mu \mathrm{m}$ (Hook et al. 1998). Consequently, TIR region $(8 \mu \mathrm{m}-14 \mu \mathrm{m})$ is effective for this kind of study, in which the material emissive properties are predominant relative to its reflective properties (Hook et al. 2005; Li et al. 2013; Grondona et al. 2019).

The site is a very homogeneous test area, mostly because it is considered a pseudo-invariant target, and therefore suitable for the terrestrial calibration of LST retrieval by remotely sensed data (Hulley and Hook 2009). The annual precipitation is $1,323 \mathrm{~mm}$, the annual evaporation is $1,135 \mathrm{~mm}$ and the average humidity is $80 \%$, according to Tramandaí Meteorological station, located around $6 \mathrm{Km}$ away from the studied area (Käfer et al. 2019).

\subsection{Data acquisition}

Nine Landsat 8 OLI/TIRS scenes were downloaded over the study area with clear-sky conditions from the US Geological Survey website <(http://earthexplorer.usgs.gov/) > in Level 1 product (Table 1). Landsat Level 1 data are radiometric, geometric and terrain corrected. To obtain the normalized difference vegetation index (NDVI), which is 
used in the LSE derivation, Landsat 8 OLI surface reflectance product was also downloaded from the Landsat data collection (see section 2.4.6).

Table 1. Information of the Landsat 8 scenes used in the study.

\begin{tabular}{ccccc}
\hline Acquisition Date & GMT Time & Path & Row & Sun Elevation \\
\hline 20 May 2019 & $13: 11: 53.75$ & 220 & 81 & $31.55^{\circ}$ \\
\hline 01 March 2019 & $13: 11: 56.99$ & 220 & 81 & $50.24^{\circ}$ \\
\hline 28 January 2019 & $13: 12: 02.98$ & 220 & 81 & $56.07^{\circ}$ \\
\hline 27 December 2018 & $13: 12: 08.78$ & 220 & 81 & $60.71^{\circ}$ \\
\hline 11 December 2018 & $13: 12: 08.72$ & 220 & 81 & $62.27^{\circ}$ \\
\hline 09 November 2018 & $13: 12: 12.15$ & 220 & 81 & $61.43^{\circ}$ \\
\hline 06 September 2018 & $13: 11: 51.21$ & 220 & 81 & $42.59^{\circ}$ \\
\hline 18 June 2018 & $13: 11: 11.95$ & 220 & 81 & $27.99^{\circ}$ \\
\hline 17 May 2018 & $13: 11: 15.28$ & 220 & 81 & $32.01^{\circ}$ \\
\hline
\end{tabular}

The Landsat project provides an opportunity for the LST retrieval because it has a relatively long data record period, with the launch of Landsat 3 in 1978. From the Multispectral Scanner (MSS) of Landsat 3 to the Thematic Mapper (TM) of Landsat 4 and 5, and following by the Enhanced Thematic Mapper Plus (ETM+) of Landsat 7, there was only one thermal infrared channel available (Huang et al. 2010).

Landsat 8 was launched as the Landsat Data Continuity Mission on 11 February 2013. The satellite carries two push-broom instruments, the Operational Land Imager (OLI) and the Thermal Infrared Sensor (TIRS) (Duan et al. 2015). OLI has eight channels located from the visible to the short-wave infrared region, whereas TIRS has two channels in the thermal infrared region of the electromagnetic spectrum (see Table 2). Landsat-8 OLI and TIRS data products are distributed as quantized calibrated digital numbers (DNs) in 16-bit unsigned integer format (Chatterjee et al. 2017).

The two spectrally adjacent Landsat 8 bands were designed to allow the users to apply SW LST retrieval methods. Due to larger calibration uncertainty caused by a significant stray light problem in TIRS band 11, it was not recommended for LST retrieval by SW methods for a long time (Montanaro et al. 2014; Yu et al. 2014; Du et al. 2015). Meanwhile, the researchers kept focusing on improving and studying the performance of SC techniques (Jiménez-Muñoz et al. 2014; Wang et al. 2015; Cristóbal et al. 2018; Käfer et al. 2019). Currently the issue is already solved and the SW methods are encouraged.

Table 2. Landsat 8 instrument's technical specifications.

\begin{tabular}{cccc}
\hline Subsystem & Band & Wavelength range $(\mu \mathrm{m})$ & Spatial resolution \\
\hline Aerosol & 1 & $0.435-0.451$ & $30 \mathrm{~m}$ \\
\hline Visible and & 2 & $0.452-0.512$ & $30 \mathrm{~m}$ \\
\hline Near Infrared & 3 & $0.533-0.590$ & $30 \mathrm{~m}$ \\
\hline (VNIR) & 4 & $0.636-0.673$ & $30 \mathrm{~m}$ \\
\hline & 5 & $0.851-0.879$ & $30 \mathrm{~m}$ \\
\hline Short Wave & 6 & $1.566-1.651$ & $30 \mathrm{~m}$ \\
\hline Infrared (SWIR) & 7 & $2.107-2.294$ & $100 \mathrm{~m}$ \\
\hline Thermal Infrared & 10 & $10.60-11.19$ & $100 \mathrm{~m}$ \\
\hline (TIR) & 11 & $11.50-12.51$ & $15 \mathrm{~m}$ \\
\hline Pan & 8 & $0.503-0.676$ & $30 \mathrm{~m}$
\end{tabular}


For LST retrieval using the SW algorithm, the two thermal available radiance bands were used. In contrast, for the application of the SC method the band 10 was chosen as input because it is in a lower atmospheric absorption region (high atmospheric transmissivity values) (Jiménez-Muñoz et al. 2014), providing superior results in comparison to the band 11 (Yu et al. 2014). The summary steps of the study are shown in the following flowchart (Figure 2).

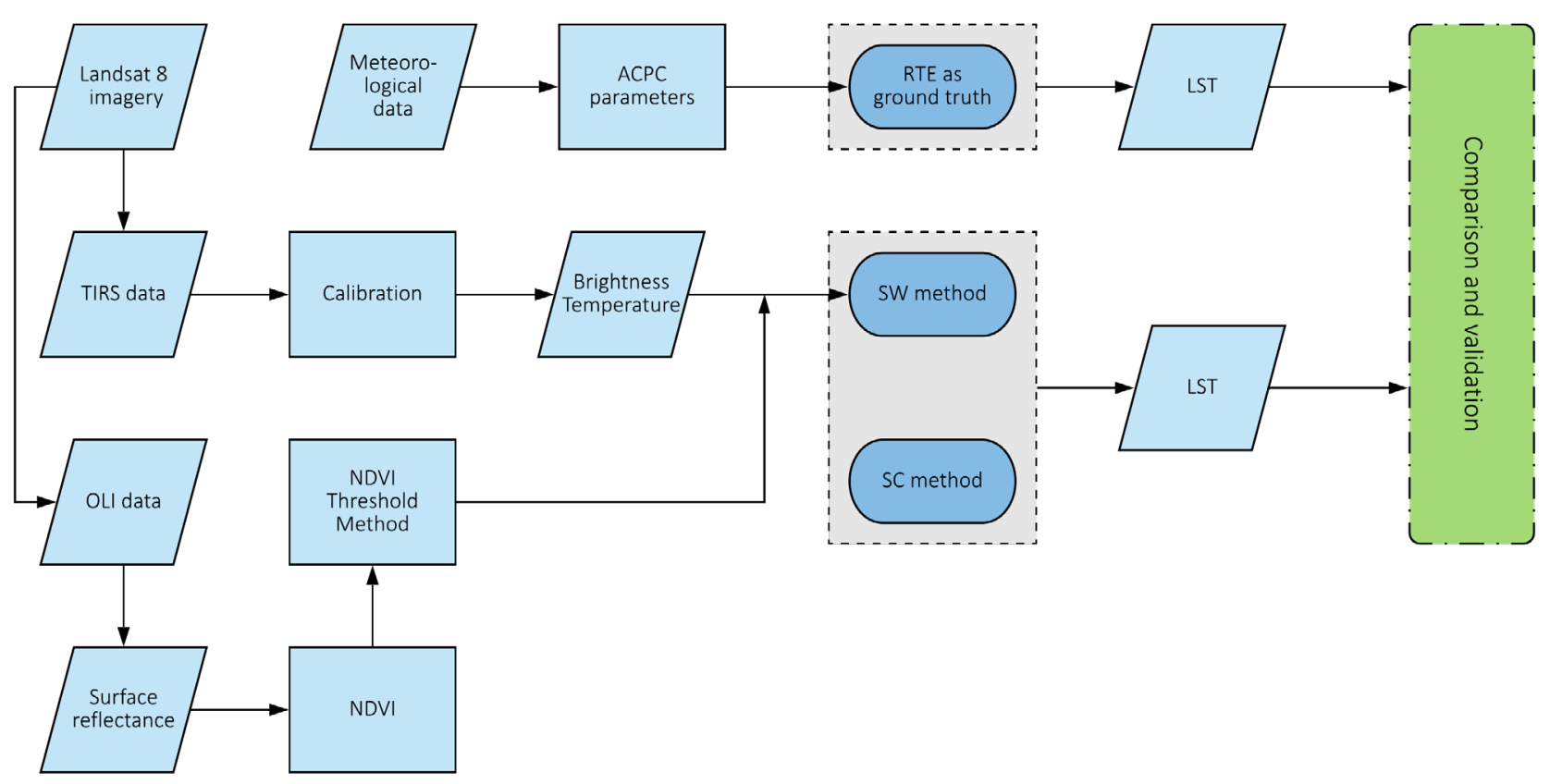

Figure 2: Flowchart with the main steps of the study.

\subsection{LST determination}

The SW algorithm applied in this paper was proposed by Jiménez-Muñoz et al. (2014) based on the mathematical structure proposed by Sobrino et al. (1996). The SC algorithm is based on the RTE (Eq. 1) and was originally developed by Jiménez-Muñoz et al. (2003) and improved in Cristóbal et al. (2018) by adding a new parameter to the model: the atmospheric mean temperature (Ta). This section will present the steps required to determinate LST from Landsat 8 images using both algorithms.

\subsubsection{Conversion of Digital Numbers to Radiance}

The thermal data in satellite imagery sensors are stored in DNs, which are used to represent pixels that have not yet been calibrated into meaningful units. They are a representation of different levels of radiance in a raster image (Ndossi and Avdan, 2016). Hence, digital number (DN) of the sensor were converted to spectral radiance using the following equation

$$
L_{\text {sen }, \lambda}=M L Q_{c a l}+A L
$$

where $L$ sen is the top of atmosphere radiance in $\mathrm{W} /\left(\mathrm{m}^{2} . \mathrm{sr} . \mu \mathrm{m}\right) ; M L$ is the band-specific multiplicative factor, $A L$ is the band-specific additive rescaling factor, and Qcal are the pixel values (DNs).

\subsubsection{Conversion of Radiance to Brightness Temperature}

Then next step consists of converting the TIR data to brightness temperature by using 


$$
T_{\text {sen }}=\frac{K_{2}}{\ln \left(\frac{K_{1}}{L_{\text {sen }}}+1\right)}
$$

where $T$ sen is the satellite brightness temperature in Kelvin, $K 1$ and $K 2$ are the band-specific conversion constant taken from the metadata file $(K 1=774.8853$ and $K 2=1321.0789$ for the Landsat 8 band $10 ; K 1=480.8883$ and $K 2=1201.1442$ for the band 11 ).

\subsubsection{SW algorithm}

SW algorithms are also called multi-channel methods and use the different absorptions of two TIR channels, linearizing or nonlinearizing RTE with respect to the temperature or wavelength (Jin et al. 2015). According to Jiménez-Muñoz et al. (2014) the SW algorithm applied in this study is calculated by

$$
\begin{aligned}
L S T=T i_{\text {sen }}+ & 1.378\left(T i_{\text {sen }}-T j_{\text {sen }}\right)+0.183\left(T i_{\text {sen }}-T j_{\text {sen }}\right)^{2}-0.268 \\
& +(54.3-2.238 w)(1-\varepsilon)+(-129.2+16.4 w) \Delta \varepsilon
\end{aligned}
$$

where $T i_{\text {sen }}$ and $T j_{\text {sen }}$ are the at-sensor brightness temperatures at the bands I and $\mathrm{j}$ (10 and 11) in Kelvins, $\varepsilon$ is the mean emissivity, $\varepsilon=0.5(\varepsilon \mathrm{i}+\varepsilon \mathrm{j}), \Delta \varepsilon$ is the emissivity difference, $\Delta \varepsilon=(\varepsilon \mathrm{i}-\varepsilon \mathrm{j})$, $w$ is the total atmospheric water vapor content (in $\mathrm{g} \cdot \mathrm{cm}^{-2}$ ).

\subsubsection{SC algorithm}

The single-channel (SC) algorithm applied here is an improved single-channel methodology that has been shown superior performance when compared to the classic SC method purposed by Jiménez-Muñoz (2014). The method retrieves LST from the following equation

$$
L S T=\gamma\left[\frac{1}{\varepsilon}\left(\psi_{1} L_{s e n}+\psi_{2}\right)+\psi_{3}\right]+\delta
$$

Where $\varepsilon$ is the land surface emissivity (LSE), $\gamma$ and $\delta$ are variables based on the Planck's function given by

and

$$
\gamma=\left\{\frac{C_{2} L_{\text {sen }}}{T_{\text {sen }}^{2}}\left[\frac{\lambda^{4} L_{\text {sen }}}{C_{1}}+\frac{1}{\lambda}\right]\right\}^{-1}
$$

$$
\delta=-\gamma L_{\text {sen }}+T_{\text {sen }}
$$

Where $C 1$ and $C 2$ are physical constants (given in Eq. 3 ); $\lambda$ is the effective wavelength of Landsat 8 band 10. Cristóbal et al. (2018) demonstrated that $\psi 1, \psi 2$, and $\psi 3$ for Landsat- 8 TIRS band 10 have a better estimate if derived as a function of both $w$ and $T a$. Thus, the three said parameters are calculated as follows:

$$
\begin{gathered}
\psi_{1}=-7.2122 w^{2}+0.00005 T_{a}^{2}-2.452321 w-0.026275 T_{a}-0.00005 T_{a}^{2} w+0.02317 T_{a} w \\
+0.04663 T_{a} w^{2}-0.00007 T_{a}^{2} w^{2}+4.47297 \\
\psi_{2}=89.61569 w^{2}-0.00038 T_{a}^{2}+106.55093 w+0.21578 T_{a}+0.00141 T_{a}^{2} w \\
-0.78444 T_{a} w-0.5732 T_{a} w^{2}+0.00091 T_{a}^{2} w^{2}-30.37028, \\
\psi_{3}=-14.65955 w^{2}-0.0001 T_{a}^{2}-79.95838 w+0.04181 T_{a}-0.00091 T_{a}^{2} w+0.54535 T_{a} w \\
+0.09114 T_{a} w^{2}-0.00014 T_{a}^{2} w^{2}-3.76184 .
\end{gathered}
$$

\subsubsection{Water vapor content}

Both SW and SC methods need the water vapor content $(w)$ in the atmosphere as input. Usually we are unable to obtain this variable in situ. However, according to Wang et al. (2015) a way of solving this problem is to use the air humity $(H)$ and air temperature $(T a)$ from a meteorological station. 
The input data required in the methodology were taken from a nearby atmospheric observation station of the Brazilian National Institute of Meteorology (INMET) <http://www.inmet.gov.br/portal/>, which is located $6 \mathrm{Km}$ away from the study area (station coordinates: $30.010268^{\circ} ;-50.135887^{\circ}$ and $5 \mathrm{~m}$ a.s.l.). Thus, $w$ in the atmosphere column up to satellite altitude can be estimated as

$$
w=\frac{w(0)}{R w(0)}
$$

where $w$ is the water vapor content $\left(\mathrm{g} \cdot \mathrm{cm}^{-2}\right)$ in the atmospheric column up to the sensor, $w(0)$ is the water vapor content $\left(\mathrm{g} \cdot \mathrm{cm}^{-2}\right)$ at the ground of the atmosphere and $R w(0)$ is the ratio of water vapor content at the first layer to the total. The ratio may differ for different atmospheres, with $\operatorname{Rw}(0)=0.6834$ for tropical atmosphere, $\operatorname{Rw}(0)$ $=0.6819$ and $\operatorname{Rw}(0)=0.6593$ for subtropical summer and winter atmospheres, respectively, and $\operatorname{Rw}(0)=0.6834$ and $\operatorname{Rw}(0)=0.6356$ for mid-latitude summer and winter atmospheres, respectively (Qin et al. 2001). In this study, we used the values for mid-latitude summer and winter according to the image date. Ultimately, the water vapor content at the ground is computed as

$$
w(0)=\frac{H * E * A}{1000}
$$

where $H$ is air humidity (\%) at the ground, $E$ is the saturation mix ratio $(\mathrm{g} / \mathrm{kg})$ of water vapor and air for a specific air temperature and $A$ is the air density $\left(\mathrm{g} / \mathrm{m}^{3}\right)$ at the specific air temperature.

\subsubsection{Land surface emissivity estimation}

LSE is the ration between radiance emitted by the land surface and the radiance emitted by a black body at the same temperature (Li et al. 2013; Rozenstein et al. 2015). Its prior knowledge is necessary in the calculation of LST from remotely sensed data.

An operational way to estimate LSE is using the NDVI threshold method (NDVI ${ }^{T H M}$ ) (Sobrino et al. 2008). This method is based on the principle that there is a relationship between the Normalized Difference Vegetation Index (NDVI) and the emissivities of terrestrial materials (Van de Griend and Owe 1993).

In general, NDVI is considered as one of the most widely used vegetation index. Areas of bare rock, sand and soil usually show very low NDVI values $(\leq 0.1)$. Sparse vegetation such as shrubs, grasslands or senescing crops give moderate NDVI values (e.g., 0.2-0.5). High NDVI values (e.g., >0.5-0.9) correspond to dense vegetation cover (Chatterjee et al. 2017).

$\mathrm{NDVI}^{\text {THM }}$ assumes that the surface is composed only of soil and vegetation. For NDVI values lower than 0.2 , pixels are entirely of soil and the emissivity of bare soil is assigned. As in this study the region is composed of $99.53 \%$ quartz according to previous analysis (Käfer et al. 2019), the emissivity attributed to these pixels was based on a pure quartz spectrum acquired from the Aster Spectral Library Version $2.0<\mathrm{http}: / /$ speclib.jpl.nasa.gov>.

Afterwards, we weighted the data by the sensor spectral response function (SRF), since it might be a potential source of uncertainties in the LSE estimation if it is not considered (Cristóbal et al. 2009; Chen et al. 2016). The equation for the SRF is defined as

$$
\varepsilon_{(\lambda)}=\frac{\int_{\lambda S}^{\lambda E} R(\lambda) \varepsilon(\lambda) d \lambda}{\int_{\lambda S}^{\lambda E} R(\lambda) d \lambda}
$$

where $R()$ is the SRF of the band, given in a discrete form with a finite range, while ${ }_{S}$ and ${ }_{\mathrm{E}}$ are the start and the end wavelengths of the band. () is the emissivity spectra of the band.

For NDVI values higher than 0.5 , the pixel is considered to be fully vegetated, thus assuming the typical emissivity value of 0.99 (Sobrino et al. 2008). For NDVI values within the described range $(0.2 \leq N D V I \leq 0.5)$ the 
pixels are considered as mixing pixels, and their emissivity is calculated trough the simplified equation proposed by Sobrino et al. (2004)

$$
\varepsilon=\varepsilon_{V \lambda} P_{V}+\varepsilon_{S}\left(1-P_{V}\right)+d \varepsilon \lambda
$$

Where $P v$ is the vegetation proportion, which means the percentage of the vertical projection of vegetation canopy per unit area and can be calculated according Carlson and Ripley (1997) equation. The term $d \varepsilon$ includes the effect of the geometrical distribution of the natural surfaces and the internal reflections ( $d \varepsilon=0$ for flat surfaces). For heterogeneous and rough surfaces, it can reach a value of $2 \%$ (Li et al. 2013).

$$
d \varepsilon=\left(1-\varepsilon_{S}\right)\left(1-P_{V}\right) F \varepsilon_{V}
$$

where $F$ is a shape factor whose mean value, assuming different geometrical distributions, is 0.55 .

\subsection{Data analysis and validation}

Since no in situ measurements for LST at the time of the Landsat 8 data acquisition are available, the RTE (Eq. 1) was assumed as ground truth to perform the validation against the algorithms tested. ACPC provides specific atmospheric parameters for the Landsat 8 TIRS thermal bands, which are required to solve the RTE. Data from the Tramandaí meteorological station were also used as input data in the ACPC to generate the variables: transmittance $(\tau)$, downwelling $(L \downarrow)$ and upwelling radiance $(L \uparrow)$.

The ACPC tool takes the National Centers for Environmental Prediction modeled atmospheric profiles as input to the MODTRAN radiative transfer code (Barsi et al. 2005). Furthermore, studies have reported that ACPC validation demonstrated that it can achieve good results in the LST retrieval (Barsi et al. 2005; Jiménez-Muñoz et al. 2010; Zhang et al. 2016).

Image processing was automated through the development of algorithms in a MATLAB environment. The comparisons between the LST retrieved by the algorithms and the ACPC results were performed through an analysis of the minimum, maximum and mean values and standard deviation $(\sigma)$ of LST. The same vector from the dune area (Figure 1) was applied to clip all the nine scenes.

Thereafter, a linear function was applied to fit the data. To evaluate the performance of the functions, the coefficient of determination $\left(\mathrm{R}^{2}\right)$ at $95 \%$ probability was used. An assessment was also made by the determination of RMSE (Root Mean Square Error), MSD (Mean standard deviation) and Bias. Ultimately, we applied the one-way analysis of variance (ANOVA) (Lee and Wang, 2013; Yu et al. 2014) to identify if the results are statistically significant.

\section{Results and discussion}

The Radiative Transfer Equation - RTE (Eq 1.) was used as reference to validate the data from both algorithms SW and SC in this work because to solve it there is a need for information about the atmospheric state at the time of the satellite overpass (Sobrino et al. 2004; Li et al. 2013; Meng et al. 2018). In this sense, the web-based ACPC is a very useful tool to obtain this kind of information (Zhang et al. 2016), since it allows to acquire the required atmospheric parameters in the RTE for each region, time and date.

As the RTE needs the radiance measured by the sensor from a single band, it is considered a SC method as well (Jiménez-Muñoz et al. 2014). We decided to use the radiance measured from TIRS channel 10 in accordance to other works (Coll et al. 2012; Yu et al. 2014; Chatterjee et al. 2017). The choice of band 10 is associated to the fact 
that it is expected that the band 11 has uncertainties for being more affected by the water vapor content $(w)$ in the atmosphere and, therefore, more sensitive to errors.

Comparing maximum, minimum and mean values of LST retrieved with the LST retrieved using RTE (Table 3), it is seen that both methods have good agreement with the RTE for most images analyzed. The variation between pixels are bigger in the hottest temperatures (01 March 2019, 28 January 2019, 27 December 2018 and 11 December 2018). All these dates belong to the summer season in the South hemisphere. Since seasonal changes affect the energy balance of ecosystems on the earth, variations in the LST behavior among seasons must be constantly investigated (Liu et al. 2017).

Table 3 also shows that the images with the coldest temperatures produced the mean values closer to the reference image (RTE). The biggest differences were found in the two December dates of 2018 (summer season), which had a difference up do 2.47 and $4.44 \mathrm{~K}$ for the SW and SC algorithms, respectively. While the dates in which we had the mean values closer to the RTE were 01 March 2019, 28 January 2019, 06 September 2018, 18 June 2018 and 17 May 2018, with results varying between -0.68 and $0.18 \mathrm{~K}$ for the SW, and 20 May 2019, 28 January 2019, 27 December 2018, 18 June 2018, 17 May 2018 with results varying from -0.44 to $0.83 \mathrm{~K}$, for the SC method.

Table 3. LST retrieved using SW and SC methods. Minimum, maximum and means values are shown. $\Delta$ refers to the difference between the means of the methods and the RTE results.

\begin{tabular}{|c|c|c|c|c|c|}
\hline Dates & Method & LST Min (K) & LST Max (K) & LST Mean (K) & $\Delta(\mathrm{K})$ \\
\hline 20 May & SW & 296.06 & 300.72 & 298.37 & 1.78 \\
\hline \multirow[t]{2}{*}{2019} & SC & 295.22 & 299.45 & 297.27 & 0.68 \\
\hline & RTE & 294.68 & 298.59 & 296.59 & - \\
\hline 01 March & SW & 299.67 & 313.29 & 306.04 & 0.06 \\
\hline \multirow[t]{2}{*}{2019} & SC & 300.75 & 314.44 & 307.61 & 1.63 \\
\hline & RTE & 300.63 & 311.44 & 305.98 & - \\
\hline 28 January & SW & 303.36 & 326.54 & 315.17 & -0.68 \\
\hline \multirow[t]{2}{*}{2019} & SC & 303.28 & 331.96 & 315.95 & 0.1 \\
\hline & RTE & 304.89 & 321.01 & 315.85 & - \\
\hline 27 December & SW & 299.65 & 316.48 & 309.39 & 2.47 \\
\hline \multirow[t]{2}{*}{2018} & SC & 298.63 & 311.76 & 306.50 & -0.42 \\
\hline & RTE & 299.23 & 312.12 & 306.92 & - \\
\hline 11 December & SW & 298.79 & 315.65 & 310.06 & 1.65 \\
\hline \multirow[t]{2}{*}{2018} & $\mathrm{SC}$ & 301.56 & 318.17 & 312.85 & 4.44 \\
\hline & RTE & 298.69 & 313.05 & 308.41 & - \\
\hline 09 November & SW & 297.05 & 310.44 & 302.62 & 1.62 \\
\hline \multirow[t]{2}{*}{2018} & SC & 297.11 & 309.41 & 302.43 & 1.43 \\
\hline & RTE & 296.35 & 307.23 & 301.00 & - \\
\hline 06 September & SW & 291.79 & 298.62 & 294.24 & 0.18 \\
\hline \multirow[t]{2}{*}{2018} & SC & 292.62 & 299.16 & 295.40 & 1.34 \\
\hline & RTE & 291.72 & 297.35 & 294.06 & - \\
\hline 18 June & SW & 286.37 & 292.06 & 288.81 & -0.21 \\
\hline \multirow[t]{2}{*}{2018} & SC & 287.77 & 292.41 & 289.85 & 0.83 \\
\hline & RTE & 287.10 & 291.47 & 289.02 & - \\
\hline 17 May & SW & 291.50 & 298.31 & 294.60 & 0.09 \\
\hline \multirow[t]{2}{*}{2018} & SC & 291.68 & 297.03 & 294.07 & -0.44 \\
\hline & RTE & 292.28 & 297.36 & 294.51 & - \\
\hline
\end{tabular}


In most images, the algorithms overestimated the LST related to the RTE. In fact, the underestimation only occurred in the dates of 28 January 2019 and 18 June 2018 for the SW, and 27 December 2018 and 17 May 2018 for the SC. Comparing both algorithms, we verified that the SW produced a slightly higher accordance in the LST means relative to the reference.

Yu et al. (2014) also reported a superior performance of the SW over the SC method. Jiménez-Muñoz et al. (2014) compared a SW and a SC methodology and verified that the SW had superior performance over the SC. Figure 3 exhibits the spatial distribution of the LST in the hottest and coldest dates analyzed for the dune area.
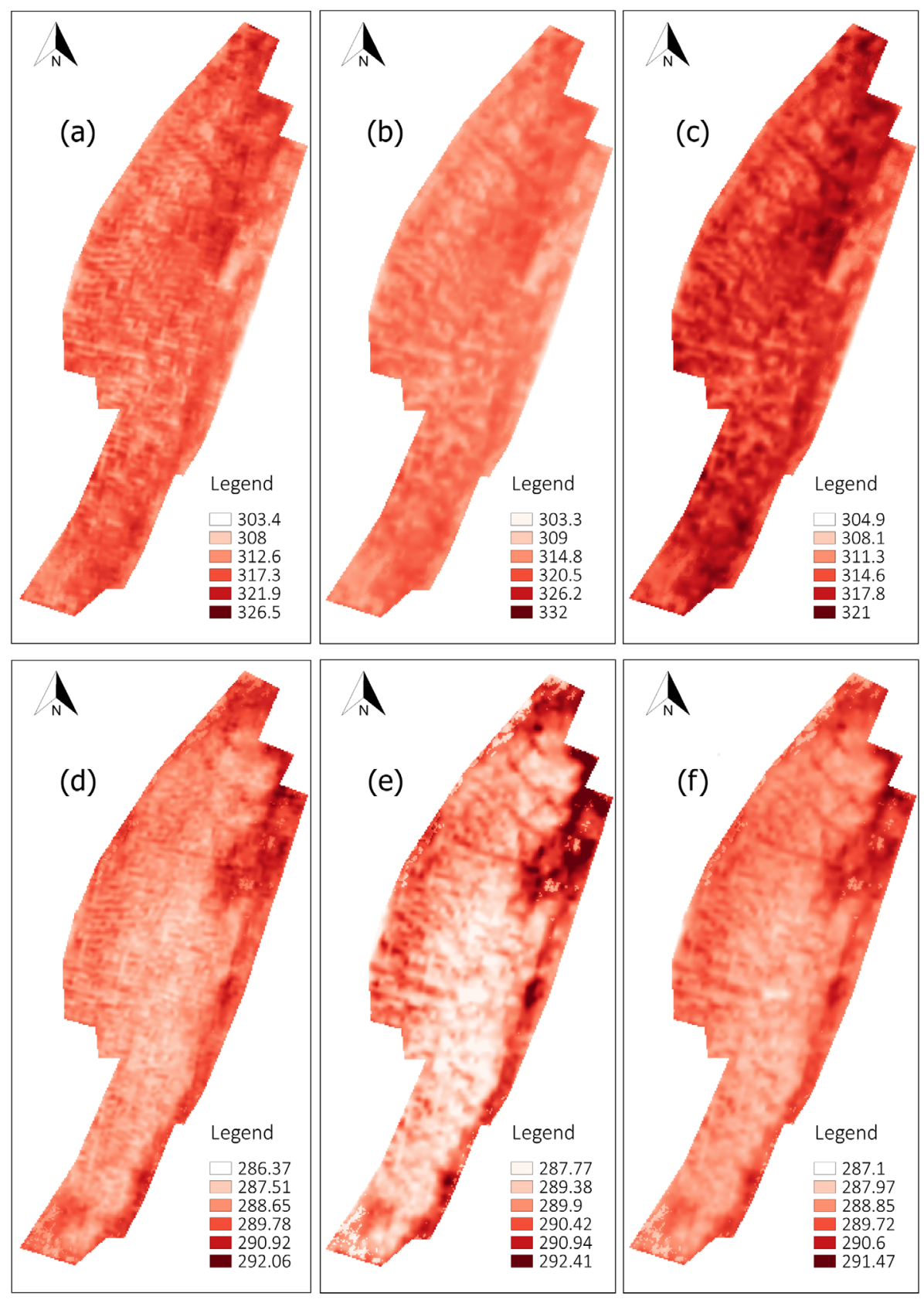

Figure 3. Spatial distribution of the Land Surface Temperature - LST of the dune area in Kelvin. (a), (b) and (c) refers to the results of the SW, SC and RTE methods, respectively, for the hottest date found (28 January 2019). (d), (e) and (f) refers to the results of the SW, SC and RTE, respectively, for the coldest date (18 June 2018). 
According to Weng et al. (2019), the amount and spatial distribution of LST in a region is influenced by environmental parameters. The input parameters required for the calculation of $w$ in both methodologies were obtained from measurements of air temperature $(T 0)$ and relative humidity for the study area, provided by the meteorological station of INMET-National Institute of Meteorology located in the municipality of Tramandaí.

These parameters resulted in a $w$ values ranging from 1.55 to $3.62 \mathrm{~g} . \mathrm{cm}^{-2}$. It is known that the algorithms, particularly the SC ones, work best when the $w$ is low. In very humid conditions (e.g., $>3 \mathrm{~g} \cdot \mathrm{cm}^{-2}$ ) they perform badly (Prata et al. 1994; Jiménez-Muñoz et al. 2003; Barsi et al. 2005; Käfer et al. 2019). However, It can be considered that none of the methodologies was effectively affected by $w$ in the retrieval of LST, since the SC method here applied is an improved algorithm, which is not sensitive to high $w$ in the atmosphere and is able to maintain a good accuracy even in situations of very high $w$ (Cristóbal et al. 2018).

When using a SC method, Souza e Silva (2005) claimed that it is possible to assume average values of Ta for a given region because there are small differences between the characteristics of the types of soil that compose the surface. In this context, the dune is a pseudo-invariant target and it is composed by 99.53 of quartz according to previous analysis done in the area. Thus, as the region evaluated is highly homogeneous and the meteorological station from where the parameters needed to correct the atmospheric effects were taken is located very close, there was certainly a good accuracy on the input data. Thus, it might have been the reason for the satisfactory performance of both methods.

Figure 3 demonstrates that the dune field has very high LST in the summer season in the South hemisphere and can achieve $321 \mathrm{~K}$ according to the RTE. In contrast, SC was the method that produced the greater number of outliers, exhibiting up to $332 \mathrm{~K}$ in the hottest day analyzed, which is probably an exceeded temperature value. Jiménez-Muñoz et al. (2014) commented that the SW algorithm tends to perform well over global conditions and a wide variety of water vapor $(w)$ values. Therefore, even that Cristóbal's method is improved to avoid errors due to high $w$ content, SW was more suitable. Figure 4 shows the results of the methods relative to the RTE.

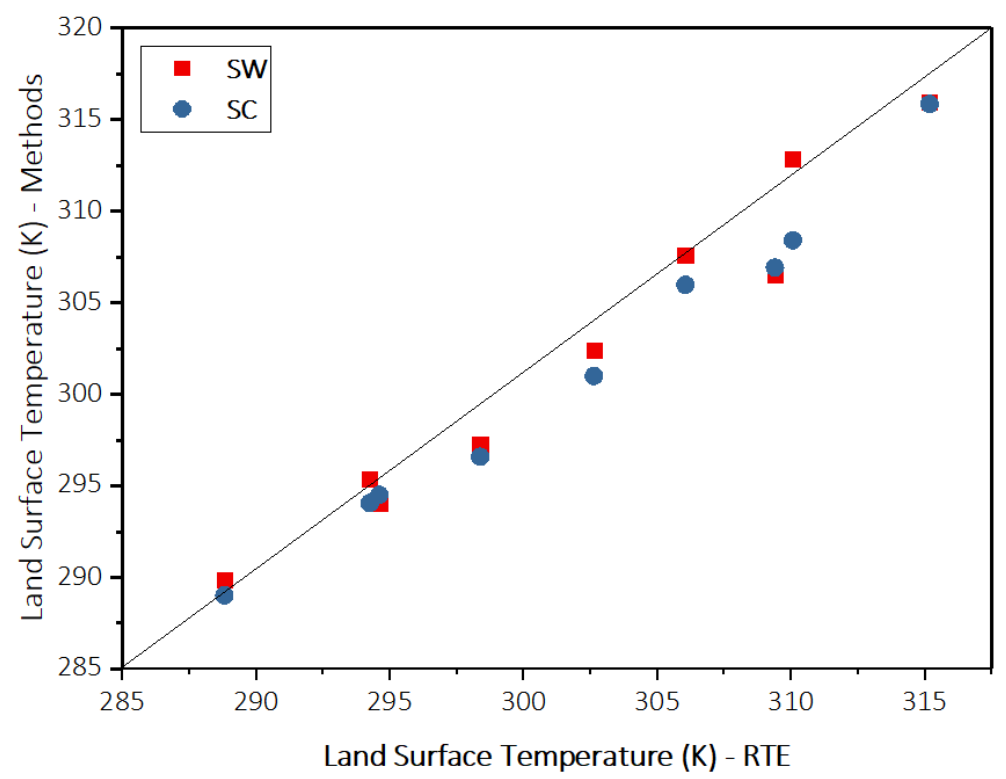

Figure 4. LST retrieved from both methods SW and SC matchups with LST retrieved by the RTE with parameters transmittance $(\tau)$, downwelling $(L \downarrow)$ and upwelling radiance $(L \uparrow)$ obtained from the ACPC tool. (1:1 Line).

It is observed that as the temperature increases, both algorithms tend to have different performances. On the other hand, in the lower temperatures they have more similar behavior. In the Table 4 the quantitative values of the methods efficiency are shown. 
The correlations between the LST retrieved and the RTE results were strong and exhibited coefficients of determination $\left(R^{2}\right)$ between 0.984 and 0.973 for the SW and SC methods, respectively. These results were expected, since we were working with a homogeneous site and almost pure target.

Yu et al. (2014) reported a RMSE of $0.90 \mathrm{~K}$ using RTE and the TIR band 10 when matching up with in situ data, which were not available in this research. Zhang et al. (2016) found a strong correlation (0.995) when evaluating SC algorithm using RTE as ground truth (same as here). Additionally, the authors reported values of RMSE varying between 0.61 and $1.24 \mathrm{~K}$. We obtained in this work a RMSE value of 1.18 and 1.6 for the SW and SC algorithms, respectively, thus consolidating the better performance of the SW over the SC method.

An analysis was also made using MSD and the Bias (Table 4). The MSD is the mean value of the standard deviation, while the Bias consists of the difference between estimated LST (SW and SC) and ground LST (RTE). The values of both found reinforce the results mentioned before. The results of Bias have shown a positive tendency, which means that they overestimate the LST. SW showed the best results for all analysis, producing an MSD of \pm 0.983 and $a$ Bias of 0.773 .

Table 4. Statistical analysis of all scenes through the Coefficient of determination $\left(R^{2}\right)$, the Root Mean Square Error (RMSE), Mean standard deviation (MSD) and Bias.

\begin{tabular}{ccc}
\hline & SW & SC \\
$\mathrm{R}^{2}$ & 0.984 & 0.973 \\
$\mathrm{RMSE}$ & 1.176 & 1.559 \\
MSD & \pm 0.983 & \pm 1.017 \\
Bias & 0.773 & 1.065 \\
\hline
\end{tabular}

Finally, ANOVA was applied for all methods and showed a f-value and p-value of 0.035 and 0.965 respectively, which indicates that at the 0.05 level the population means do not have statistical significance.

It consolidates the comparison using $\mathrm{R}^{2}$, RMSE, MSD and Bias as mentioned by Yu et al. (2014). The box plot of the LSTs is shown in Figure 5. These values indicate that we can obtain an acceptable accuracy for LST retrieval by applying the two methodologies in our region. However, SW algorithm is more indicated, since it displayed superior results in all analysis performed in this work.

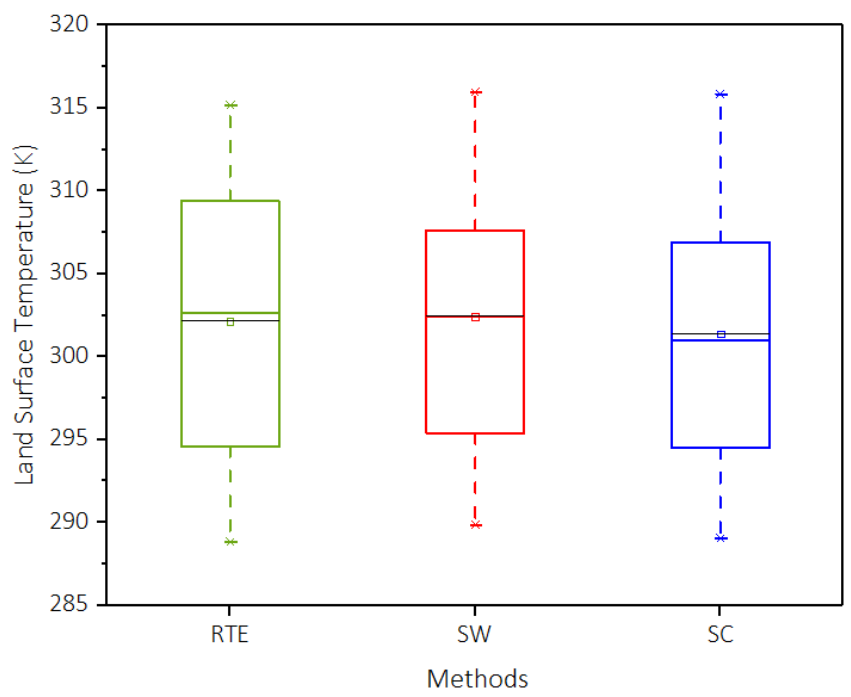

Figure 5. Box plot of the LSTs means. 


\section{Conclusions}

This paper explores two operational methods of LST retrieval from Landsat 8 images of a pseudo-invariant target in Southern Brazil. The methodologies here tested require the parameters water vapor content in the atmosphere $(w)$, atmospheric mean temperature $(T a)$ and land surface emissivity (LSE) as input data, which can be obtained only from image data and measurements of meteorological stations. Since no measurements in situ were available, the radiative transfer equation (RTE) was used as reference and its needed variables were retrieved using ACPC tool (Barsi et al. 2005).

The methods SW and SC showed good agreement with the RTE for most scenes analyzed, although both overestimated the LST. The hottest temperatures, which corresponded to the summer season in the Southern hemisphere, had bigger variation between pixels. In contrast, the coldest temperatures produced the values closer to the reference image (RTE). The one-way analysis of variance (ANOVA) indicated that at the 0.05 level the population means does not have statistical significance, which consolidates the comparisons using $\mathrm{R}^{2}, \mathrm{RMSE} \mathrm{MSD}$ and Bias.

The correlations between the LST retrieved and the RTE were strong and produced coefficients of determination $\left(R^{2}\right)$ of 0.984 and 0.973 for the SW and SC algorithms, respectively. Furthermore, RMSE values of 1.18 and 1.6 for the SW and SC were found. The results of Bias showed a positive tendency for both methods, which means that they overestimated the LST. SW also exhibited the best values of MSD ( \pm 0.983$)$ and Bias $(0.773)$, thus reinforcing the superior performance of the SW over the SC method.

The SW algorithm tends to perform well over global conditions and a wide variety of water vapor $(w)$ values (Jiménez-Muñoz et al. 2014). Therefore, even that the SC method here applied is an improved methodology to avoid errors due to high $w$ content, SW was more suitable relative to the RTE and can be applied with an accuracy of 1.18 $\mathrm{K}$ in the Southern Brazil, without needing complex modeling or specific radiosonde data launched at the time of the satellite overpass.

These are simple comparisons using currently available data as preliminary validation efforts. In further study more ground truth data will be added to make a reasonable conclusion for validation of products. In future research we also intend to evaluate the performance of the algorithms in a more extensive time series and across different seasons.

\section{ACKNOWLEDGMENT}

The Landsat 8 OLI/TIRS products are a courtesy of the US Geological Survey Earth Resources Observation and Science Center. This study was financed in part by the "Coordenação de Aperfeiçoamento de Pessoal de Nível Superior" (CAPES), finance code 001, and the "Conselho Nacional de Desenvolvimento Científico e Tecnológico" (CNPq), Brazil.

\section{AUTHOR'S CONTRIBUTION}

P. S. Käfer and S. B. A. Rolim designed the framework of this research work. P. S. Käfer, N. S. da Rocha, L. R. Diaz and M. L. Iglesias processed the major data sources and drafted the preliminary version of the paper. P. S. Käfer, S. B. A. Rolim and F. E. Rex revised the paper. 


\section{REFERENCES}

Barsi, J. A.; Schott, J. R.; Palluconi, F. D.; Hook, S. J. Validation of a Web-Based Atmospheric Correction Tool for Single Thermal Band Instruments. In: Earth Observing Systems X, edited by James J. Butler, Proceedings of SPIE, v. 5882, 2005.

Bisquert, M.; Sánchez, J. M.; Caselles, V. Evaluation of Disaggregation Methods for Downscaling MODIS Land Surface Temperature to Landsat Spatial Resolution in Barrax Test Site. IEEE Journal of Selected Topics in Applied Earth Observations and Remote Sensing, v. 9, n. 4, p. 1430 - 1438, 2016.

Carlson, T. N. and Ripley, D. A. On the relation between NDVI, fractional vegetation cover, and leaf area index. Remote Sensing of Environment. v. 62, n.3, p. 241-252, 1997.

Chatterjee, R. S.; Singh, N.; Thapa, S.; Sharma, D.; Kumar, D. Retrieval of land surface temperature (LST) from Landsat TM6 and TIRS data by single channel radiative transfer algorithm using satellite and ground-based inputs. International Journal of Applied Earth Observation and Geoinformation, v. 58, p. 264-277, 2017.

Chen, F.; Yang, S.; Su, Z.; Wang, K. Effect of emissivity uncertainly on surface temperature retrieval over urban areas: Investigations based on spectral libraries. ISPRS Journal of Photogrammetry and Remote Sensing, v. 114, p. 53-66, 2016.

Coll, C.; Caselles, V.; Valor, E.; Niclòs, R. Comparison between different sources of atmospheric profiles for land surface temperature retrieval from single channel thermal infrared data. Remote Sensing of Environment. v. 117, p. 199-210, 2012.

Cristóbal, J.; Jiménez-Muñoz, J. C.; Sobrino, J. A.; Ninyerola, M.; Pons, X. Improvements in land surface temperature retrieval from the Landsat series thermal band using water vapor and air temperature. Journal of Geophysical Research, v. 114, D08 103, 2009.

Cristóbal, J.; Jiménez-Muñoz, J. C.; Prakash, A.; Mattar, C.; Skokovic, D.; Sobrino, J. A. An Improved Single-Channel Method to Retrieve Land Surface Temperature from the Landsat-8 Thermal Band. Remote Sensing, v. 10, n. 431, p. 1-14, 2018.

Dash, P.; Göttsche, F.-M.; Olesen, F.-S.; Fischer, H. Land Surface Temperature and Emissivity Estimation from Passive Sensor Data: Theory and Practice-Current Trends. International Journal of Remote Sensing. v. 23, p. 2563-2594, 2002.

Du, C.; Ren, H.; Qin, Q.; Meng, J.; Zhao, S. A Practical Split-Window Algorithm for Estimating Land Surface Temperature from Landsat 8 Data. Remote sensing. v. 7, n. 1, p. 647-665, 2015.

Grondona, A.; Rolim, S. B. A. Separação de Temperatura e Emissividade a partir de imagens do Infravermelho Termal: Análise de suas Aplicações/Restrições. Bulletin of Geodetic Sciences, v. 22, n. 1, p. 16-34, 2016.

Grondona, A. E. B.; Veettil, B. K.; Rolim, S. B. A.; Gomes, L. P.; Rocha, N. S.; Käfer, P. S.; Iglesias, M. L.; Diaz, L. R.; Kaiser, E. A.; Silva, S. C. S. Retrieval of Temperature and Emissivity of Dune Fields Using Landsat8 and Quartz Spectral Library in an Iterative Approach. In: XIX Simpósio Brasileiro de Sensoriamento Remoto, 2019, Santos. XIX Simpósio Brasileiro de Sensoriamento Remoto, 2019.

Hook, S. J.; Cudahy, T. J.; Kahle, A. B.; Whitbourn, L. B. Synergy of 757 active and passive airborne thermal infrared systems for surface compo- 758 sitional mapping. Journal of Geophysical Research, v. 103, n. B8, p. 18.26918.276, 759, 1998.

Hook, S. J.; Dmochowski, J. E.; Howard, K. A.; Rowan, L. C.; Karlstrom, K. E.; Stock, J. M. Mapping variations in weight percent silica measured from multispectral thermal infrared imagery - Examples from the Hiller Mountains, Nevada, USA and TresVirgenes-La Reforma, Baja California Sur, Mexico. Remote Sensing of Environment, v. 95, p. 273-289, 2005.

Huang, C.; Goward, S. N.; Masek, J. G.; Thomas, N.; Zhu, Z.; Vogelmann, J. E. An automated approach for reconstructing recent forest disturbance history using dense Landsat time series stacks. Remote Sensing of Environment, v. 114, p. 183-198, 2010.

Hulley, C. G., and Hook, S. J. Intercomparison of versions 4, 4.1 and 5 of the MODIS Land Surface Temperature and 
Emissivity products and validation with laboratory measurements of sand samples from the Namib desert, Namibia. Remote Sensing of Environment, v. 113, n. 6, p. 1313-1318, 2009.

Jiménez-Muñoz, J. C. and Sobrino, J. A. A generalized single channel method for retrieving land surface temperature from remote sensing data. Journal of Geophysical Research. 108, 2003.

Jiménez-Muñoz, J.C.; Sobrino, J.A. Split-window coefficients for land surface temperature retrieval from lowresolution thermal infrared sensors. IEEE Geoscience Remote Sensing Letters. v. 5, p. 806-809, 2008.

Jiménez-Muñoz, J. C., J. A. Sobrino, C. Mattar, and B. Franch. Atmospheric Correction of Optical Imagery from MODIS and Reanalysis Atmospheric Products. Remote Sensing of Environment, v. 114, p. 2195-2210, 2010.

Jiménez-Muñoz, J.C.; Sobrino, J.A.; Skokovic, D.; Mattar, C.; Cristobal, J. Land surface temperature retrieval methods from Landsat-8 thermal infrared sensor data. IEEE Geoscience Remote Sensing Letters. v. 11, p. 1840-1843, 2014.

Jin, M.; Li, J.; Wang, C.; Shang, R. A Practical Split-Window Algorithm for Retrieving Land Surface Temperature from Landsat-8 Data and a Case Study of an Urban Area in China. Remote Sensing. v. 7, n. 4, p. 4371-4390, 2015.

Käfer, P. S.; Rolim, S. B. A.; Iglesias, M. L.; Rocha, N. S.; Diaz, L. R. Land Surface Temperature Retrieval by LANDSAT 8 Thermal Band: Applications of Laboratory and Field Measurements. IEEE Journal of Selected Topics in Applied Earth Observations and Remote Sensing, v. 12 n. 7, p. 2332-2341, 2019.

Kim, Y.; Malakar, N.; Hulley, G. and Hook, S. Surface Temperature Retrieval from MASTER Mid-wave Infrared Single Channel Data Using Radiative Transfer Model. Korean Journal of Remote Sensing. v. 35, n. 1, 2019.

Lee, E. T., Wang, J. W. Statistical Methods for Survival Data Analysis; John Wiley \& Sons: Hoboken, NJ, USA, 2013.

Li, Z.-L., Tang, B-H., Wu, h., Ren, H., Yan, G., Wan, Z., Trigo, I., Sobrino, J. Satellite-derived land surface temperature: Current status and perspectives. Remote Sensing of Environment, v. 131, n. 15, p. 14-37, 2013.

Li, S.; Jiang, G.-M. Land Surface Temperature Retrieval from Landsat-8 Data with the Generalized Split window Algorithm. IEEE Access, v. 6, p. 18149-18162, 2018.

Liu, W.; Feddema, J.; Hu L.; Zung, A.; Brunsell, N. Seasonal and Diurnal Characteristics of Land Surface Temperature and Major Explanatory Factors in Harris County, Texas. Sustainability. v. 9, 2324, 2017.

Malakar, N. K., Hulley, G. C., Hook, S. J., Laraby, K., Cook, M., Schott, J. R. An Operational Land Surface Temperature Product for Landsat Thermal Data: Methodology and Validation. IEEE Transactions on Geoscience and Remote Sensing. v. 56, n.10, p. 5717-5735, 2018.

Meng, X.; Cheng, J. Evaluating Eight Global Reanalysis Products for Atmospheric Correction of Thermal Infrared Sensor-Application to Landsat 8 TIRS10 Data. Remote Sensing. v. 10, n. 3, p. 474, 2018.

Montanaro, M.; Gerace, A.; Lunsford, A.; Reuter, D. Stray Light Artifacts in Imagery from the Landsat 8 Thermal Infrared Sensor. Remote Sensing. v. 6, v. 11, p. 10435-10456, 2014.

Ndossi, M. I.; Avdan, U. Application of Open Source Coding Technologies in the Production of Land Surface Temperature (LST) Maps from Landsat: A PyQGIS Plugin. Remote Sens. 2016, 8, 413.

Prata, A. J. Land surface temperature determination from satellites. Adv. Space Res. v. 14, n. 3, pp. 15-26, 1994.

Qin, Z.; Karnieli, A and Berliner, P. A mono-window algorithm for retrieving land surface temperature from Landsat TM data and its application to the Israel-Egypt border region. International Journal of Remote Sensing, v. 22, n. 18, 2001.

Rozenstein, O.; Agam, N.; Serio, C.; Masiello, G.; Venafra, S.; Achal, S.; Puckrin, E.; Karnieli, A. Diurnal emissivity dynamics in bare versus biocrusted sand dunes. Science of the Total Environment, 506-507, p. 422429, 2015.

Sánchez, J. M.; Rubio, E.; López-Serrano, F. R.; Artigao, M. M.; Caselles, V.; Moya, D. and Odi, M. M. Effect of a forest fire on the surface energy balance in a mediterranean forest area using Landsat 5-TM imagery. Revista de Teledetección, v. 32, p. 72-85, 2009.

Sheng, L.; Tang, X.; You, H.; Gu, Q.; Hu, H. Comparison of the urban heat island intensity quantified by using air temperature and Landsat land surface temperature in Hangzhou, China. Ecological Indicators, v. 72, p. 738-746, 2017. 
Sobrino, J. A.; Li, Z.-L.; Stoll, M. P.; and Becker, F. Multi-channel and multi-angle algorithms for estimating sea and land surface temperature with ATSR data. International Journal of Remote Sensing, v. 17, n. 11, p. 2089-2114, 1996.

Sobrino, J. A., Jiménez-Muñoz, J. C. and Paolini, L. Land surface temperature retrieval from LANDSAT TM5. Remote Sensing of Environment. v. 90, n. 4, p. 434-440, 2004.

Sobrino, J. A.; Jiménez-Muñoz, J. C.; Sòria, G.; Romaguera, M.; Guanter, L.; Moreno, J. Land Surface Emissivity Retrieval from Different VNIR and TIR Sensors. IEEE Transactions on Geoscience and Remote Rensing, v. 46, n. 2, 2008.

Souza, J. D.; Silva, B. B. Correção atmosférica para temperatura de superfície obtida com imagem TM - Landsat 5. Revista Brasileira de Geofísica. v. 23 n. 4, p. 349-358, 2005.

Yu, X.; Guo, X.; Wu, Z. Land Surface Temperature Retrieval from Landsat 8 TIRS-Comparison between Radiative Transfer Equation-Based Method, Split Window Algorithm and Single Channel Method. Remote Sensing. p. 9829-9852, 2014.

Van de Griend, A. A. and Owe, M. On the relationship between thermal emissivity and the normalized difference vegetation index for natural surfaces. International Journal of Remote Sensing. v.14, n. 6, p. 1119-1131, 1993.

Wang, F.; Qin, Z.; Song, C.; Tu, L.; Karnieli, A.; Zhao. S. An Improved Mono-Window Algorithm for Land Surface Temperature Retrieval from Landsat 8 Thermal Infrared Sensor Data. Remote Sensing. v. 7, n. 4, p. 4268-4289, 2015.

Weng, Q.; Fu, P. Modeling annual parameters of clear-sky land surface temperature variations and evaluating the impact of cloud cover using time series of Landsat TIR data. Remote Sensing of Environment, v. 140, p. 267-278, 2014.

Weng, Q.; Firozjaei, M. K.; Kiavarz, M. Alavipanah, S. K.; Hamzeh, S. Normalizing Land Surface Temperature for environmental parameters in mountainous and urban areas of a cold semi-arid climate. Science of the Total Environment, v. 650, p. 515-529, 2019.

Zhang, F. (a) Tiyip, T.; Kung, H.; Johnson, V. C.; Maimaitiyiming, M.; Zhou, M.; Wang, J. Dynamics of land surface temperature (LST) in response to land use and land cover (LULC) changes in the Weigan and Kuqa river oasis, Xinjiang, China. Arabian Journal of Geosciences, v. 9, p. 499, 2016.

Zhang, Z. (b) He, G., Wang, M., Long, T., Wang, G., Zhang, X., and Jiao, W. Towards an operational method for land surface temperature retrieval from Landsat 8 data. Remote Sensing Letters. v. 7, n. 3, p. 279-288, 2016.

Zhao, W.; Wi, H.; Yin, G.; Duan, S-B. Normalization of the temporal effect on the MODIS land surface temperature product using random forest regression. ISPRS Journal of Photogrammetry and Remote Sensing. v. 152, p. 109-118, 2019.

Zheng, Y.; Ren, H.; Guo, J.; Ghent, D.; Tansey, K.; Hu, X.; Nie, J.; Chen, S. Land Surface Temperature Retrieval from Sentinel3A Sea and Land Surface Temperature Radiometer, Using a Split-Window Algorithm. Remote Sensing. v. 11, n. 650, 2019. 